\title{
Comparative Study of Variations in Blood Glucose Concentration in Different Phases of Menstrual Cycle in Young Healthy Women Aged 18-22 Years.
}

\author{
${ }^{1}$ Y. S. Usha Rani M. D., ${ }^{2}$ P. Manjunath D. N. B., ${ }^{3}$ R. D. Desai M. D. \\ ${ }^{1}$ Lecturer, Department of Physiology, Mysore Medical College \&Research Institute, Mysore, Karnataka, India. \\ ${ }^{2}$ Consultant Physician, Department of General Medicine, Mysore Medical College \&Research Institute, \\ Mysore, Karnataka, India. \\ ${ }^{3}$ Professor, Department of Physiology, Navodaya Medical College, Raichur, Karnataka, India.
}

\begin{abstract}
Hormones- estrogen and progesterone control the menstrual cycle in women. These hormones also affect the blood glucose. Many women notice fluctuations in blood glucose at certain times in their monthly cycle, such as an increase in blood glucose a few days prior to the beginning of their period and then a decrease once the period begins. This increase usually occurs after ovulation and before menstruation. These changes are caused by the hormones, estrogen and progesterone. When these hormones are at their highest level just before the menstruation, they affect another important hormone, insulin, which may in turn cause the blood glucose to rise. The study was carried out to know whether or not there are any consistent variations in the blood glucose levels in women with different phases of menstrual cycle and to compare the variations in blood glucose levels in different phases of menstruation between individuals. This study included 50 healthy women aged 18-22 years with regular menstrual cycles of 23-32 days who were non smokers and non alcoholics. Colorimetric technique was used for glucose measurement, enzyme linked immune sorbent assay technique (ELISA) for measurement of hormones. The results of the present study revealed significant increase in mean $( \pm S D)$ values of serum glucose $(p<0.0001)$ and serum progesterone levels $(p<0.0001)$ with significant decrease of serum estradiol mean $( \pm S D)$ values $(p<0.0001)$ in luteal phase than follicular phase of menstrual cycle of healthy women. The rise in blood glucose concentration during luteal phase compared to follicular phase in the same subject and between the individuals indicated faster carbohydrate metabolism during follicular phase as compared to luteal phase. The reason is probably due to changes in the level of endogenous female sexual hormones particularly progesterone which causes insulin resistance.
\end{abstract}

Key words: blood glucose, menstrual cycle, female sex hormones, young healthy women.

\section{Introduction}

It is common for women with diabetes to have difficulty with blood glucose control during the week prior to their menstrual period, with glucose levels being either higher or lower than usual. This problem seems to be more prevalent in women who say they suffer from the symptoms associated with premenstrual syndrome (PMS) ${ }^{(1,2)}$.

During the first half of each cycle, levels of estrogen and progesterone hormones are relatively low. During the second part of the cycle, after ovulation, these hormone levels increase, causing the lining of the uterus to thicken in preparation for nourishing a fertilized egg. If fertilization does not happen, the ovary stops making these two hormones, and their sudden loss causes the uterus to shed the lining that is not needed; this shedding is known as menstruation ${ }^{(12)}$.

A woman's glucose levels are controlled by certain hormones, just as hormones regulate the menstrual cycle. Indeed, the interference between certain hormones can lead to irregular blood sugar levels. For women with both type 1 diabetes as well as those with type 2 diabetes, fluctuations in blood glucose levels that are associated with menstruation can be a cause for concern ${ }^{(3)}$. Most commonly, women with diabetes will experience a rise in blood glucose levels the week prior to menstruation, just after ovulation. Once a woman's period begins, her blood sugar levels will tend to drop. This fluctuation is caused by a rise in estrogen and progesterone levels, which interfere with insulin activity ${ }^{(4)}$

Many studies ${ }^{(5,9)}$ recommended that women with diabetes monitor changes resulting from menstruation the same way they would monitor blood glucose levels. In order to find a correlation between menstruation and diabetes, make a note of the onset of your period in your blood glucose record book, and watch for any emerging patterns between glucose levels and the menstrual cycle over time. Women with diabetes should already be keeping a record book as part of a standard diabetes management. Women with type 1 diabetes (who should be recording glucose levels at least four times a day) will tend to experience the most fluctuations in the fasting blood glucose measured before breakfast just prior to the onset of menstruation ${ }^{(13)}$. 


\section{Subjects And Methods}

This study was conducted at the department of Physiology, Mysore Medical College and Research Institute, Mysore.

A total of 50 female students studying their MBBS Course in Mysore Medical College, Mysore were selected. The selected students were in the age group 18-22 years who were having regular, 28-day menstrual cycles for at least 6 months prior to this study. After detailed enquiry of the medical history of the subjects, those with history of smoking, alcoholism, medical illness were excluded. Subjects on oral contraceptive pill, hormonal replacement therapy were also excluded from the study. Informed written consent was obtained from all participants, and the experiment protocol was approved by Ethics Committee of the college.

Venous blood $(5 \mathrm{ml})$ was collected during the follicular phase (5-11 days of menstrual cycle) and the luteal phase of the cycle (19-28 days of menstrual cycle). Serum glucose concentration, serum estradiol, progesterone were measured during follicular and luteal phase of the cycle. Colorimetric technique was used for glucose measurement, enzyme linked immune sorbent assay technique (ELISA) for measurement of hormones. Statistical analysis:

The statistical analysis was done student's paired $\mathrm{T}$ test. $\mathrm{P}$ value less than 0.0001 was taken as significant.

\section{Results}

The mean $( \pm \mathrm{SD})$ of serum glucose, estradiol, and progesterone concentration are illustrated in table: 1

\begin{tabular}{|l|l|l|}
\hline & $\begin{array}{l}\text { On follicular phase (5-11 days of } \\
\text { menstrual cycle) }\end{array}$ & $\begin{array}{l}\text { On luteal phase (19-28 days of } \\
\text { menstrual cycle) }\end{array}$ \\
\hline Serum glucose $(\mathrm{mg} / \mathrm{dl})$ & $91.14 \pm 4.93$ & $111.26 \pm 5.89^{\circ}$ \\
\hline Serum estradiol $(\mathrm{pg} / \mathrm{ml})$ & $302.54 \pm 6.66$ & $102.26 \pm 6.06^{\circ}$ \\
\hline Serum progesterone $(\mathrm{ng} / \mathrm{ml})$ & $0.97 \pm 0.29$ & $26.12 \pm 6.79^{\circ}$ \\
\hline
\end{tabular}

${ }^{*} \mathrm{p}<0.0001$

Significant increase observed in glucose concentration of healthy female with regular menstrual cycle with $(\mathrm{p}<0.0001)$, as well as significant increase observed in progesterone concentration of healthy female with regular menstrual cycle with $(p<0.001)$, while it was found significant decrease in estradiol level $(p<0.0001)$ during the luteal phase in comparison with follicular phase of menstrual cycle. It was found that $22 \%$ of these 50 healthy female with regular menstrual cycle showed elevation in serum glucose concentration (reference value $100 \mathrm{mg} / \mathrm{dl}$ ) with mean

$107 \mathrm{mg} / \mathrm{dl}$ during the luteal phase of menstrual cycle, while the reminders have normal glucose concentration during this period.

\section{Discussion}

Women with diabetes frequently report problems with blood glucose control around the time of menstruation. In the present study, healthy women showed that $22 \%$ of them have high levels of glucose during the luteal phase, while the rest have no significant change in either phases, probably may be related to the changes in female hormones (estrogen and progesterone) throughout the menstrual cycle ${ }^{(13)}$. One theory is that increased levels of progesterone cause increased insulin resistance. In turn this leads to hyperglycemia, while the decrease of glucose concentration during follicular phase can be concerned to high estrogen causing increased insulin sensitivity ${ }^{(6)}$.

The results of the present study are in agreement with other studies ${ }^{(15,18)}$ which reported that many factors have been attributed to this phenomenon. These studies have reported elevated progesterone levels during premenstrual hyperglycemia and suggested that premenstrual symptoms may explain the unsatisfactory blood glucose control found during this period.

Other studies ${ }^{(7,16)}$ which showed that it is possible that eating patterns change in the week before menstrual cycle and affect glucose levels; that women often have increased appetites and cravings during the days leading up to menstruation "many women experience cravings for high-carbohydrate foods during the late luteal phase of their cycle", However these studies suggest that this cannot be the sole cause of premenstrual hyperglycemia.

Many studies ${ }^{(10,14)}$ found that progesterone is thought to be the main culprit in decreased insulin sensitivity during the luteal, or post-ovulation, phase, it's not completely understood. The hormone progesterone plays a vital role in controlling blood sugar levels. One of the many functions of progesterone is blood sugar regulation in all vertebrates. If the level becomes either too high or too low, loss of consciousness occurs, followed by death. Blood sugar imbalances are an increasingly common problem and in some measure can be laid at the door of hormone imbalances. The other theory reported that the variation in insulin sensitivity over the menstrual cycle was minimal and probably associated with psychological stress ${ }^{(11,20)}$ and have correlated psychological stress, presented as constituting part of the premenstrual syndrome in some diabetic women, with poor metabolic control including diabetic ketoacidosis and hypoglycemia during this period. These 
investigators even suggested that treatment of the premenstrual syndrome may mitigate any menstrual cyclerelated effects, improving insulin sensitivity and blood glucose control

The study is in disagreement with other study ${ }^{(8,17)}$ which compared 10 male and 20 female type 1 diabetes patients, using diaries in which variations in insulin dose were recorded. These investigators failed to detect any statistically significant difference in insulin sensitivity related to gender or to the phases of the menstrual cycle. Moreover, they suggested that changes in metabolic control during the menstrual cycle are probably attributable to Metabolic Control.

\section{Conclusion}

The study revealed that blood glucose level changes along the period of menstrual cycle, due to the interaction between the hormones that control menstruation (estrogen and progesterone) and the insulin hormone.

\section{References}

[1]. Bestetti GE, Locatelli V, Tirone F, Rossi GL, Muller EE (2000). One month of streptozotocin-diabetes induces different neuroendocrine and morphological alterations in the hypothalamo-pituitary axis of male and female rats. Endocrinology; 117:20816.

[2]. Buckler HM, Robertson WR, Wu FC (2005). Which androgen replacement therapy for women? Department of Endocrinology and Medicine, University of Manchester, Hope Hospital, Salford, United Kingdom. J Clin Endocrinol Metab;83:3920-4 .

[3]. Barberà A, Rodríguez-Gil JE, Guinovart JJ (1994). Insulin-like effects of tungstate in diabetic rats. J Biol Chem; 269:20047-53.

[4]. Brüning JC, Gautam D, Burks DJ, Gillete J, Schubert M, Orban PC, Klein R, Krone W, Müller-Wieland D, Kahn CR (2000). Role of brain insulin receptor in control of body weight and reproduction. Science; 289:2122-25.

[5]. Bestetti GE, Junker U, Locatelli V, Rossi GL (2002). Continuous subtherapeutic insulin counteracts hypothalamo pituitary-gonadal alterations in diabetic rats. Diabetes; 36:1315-19.

[6]. Ballester J, Muñoz MC, Domínguez J, Rigau T, Guinovart JJ, Rodríguez-Gil JE (2004). Insulin-dependent diabetes affects testicular function by FSH- and LH-linked mechanisms. J Androl ; 25:139-52.

[7]. Barfield RJ. Glaser JH. Rubin BS. Etgen AM (2004). Behavioral effects of progestin in the brain. Psychoneuroendocrinology; 9:217-31.

[8]. Billen, J., Blanckaert, N., De Moor, B., De Smet, F., D Hooghe, T., Gevaert, O., Kyama, C., Meuleman, C., Mihalyi, A., Pochet, N., Simsa, P.: WO2008049175 ( 2008 ).

[9]. Claret M, Corominola M, Saura J, Barcelo-Batllori S, Guinovart JJ, Gomis R (2005). Tungstate decreases weight gain and adiposity in obese rats through increased thermogenesis and lipid oxidation. Endocrinology ;146:4362-69.

[10]. Ding EL, Song Y, Malik VS, Liu S (2006): Sex differences of endogenous sex hormones and risk of type 2 diabetes: a systematic :1288-99.

[11]. Dahan MH \& Goldstein J (2006). Serum sex hormone-binding globulin levels show too much variability to be used effectively as a screening marker for insulin resistance in women with polycystic ovary syndrome. Fertility and Sterility;86: 934-41.

[12]. Karkanias GB, Petitti N, Etgen AM (1995). Progesterone attenuation of alpha1 -adrenergic receptor stimulation of phosphoinositol hydrolysis in hypothalamus of estrogen-primed female rats. Endocrinology; 136:1993-99.

[13]. Katsuki A, Sumida Y, Murashima S, Fujii M, Tsuchihashi K, Murata K, Yano Y \& Shima T (1996). Acute and chronic regulation of serum sex hormone-binding globulin levels by plasma insulin concentrations in male noninsulin-dependent diabetes mellitus patients. Journal of Clinical Endocrinology and Metabolism ;812515-19.

[14]. Korytkowski MT, Krug EI, Daly MA, Deriso L, Wilson JW \& Winters SJ (2005). Does androgen excess contribute to the cardiovascular risk profile in postmenopausal women with type 2 diabetes? Metabolism; 54: 1626-31.

[15]. Pleim ET, Cailliau PJ, Weinstein MA, Etgen AM, Barfield RJ (1990). Facilitation of receptive behavior in estrogen-primed female rats by the anti-progestin, RU 486. Hormones \& Behavior; 24:301-10.

[16]. Pugeat M, Moulin P, Cousin P, Fimbel S, Nicolas MH, Crave JC \& Lejeune H (1995). Interrelations between sex hormone-binding globulin (SHBG), plasma lipoproteins and cardiovascular risk. Journal of Steroid Biochemistry and Molecular Biology; 53: 567-72.

[17]. Penesova A \& Radikova Z (2004). Comparison of insulin sensitivity indices calculated fromstandard 3-sampled and frequently sampled oral glucose tolerance test. Endocrine Regulations;38:167-71.

[18]. Rees DA, Alcolado JC (2005). Animal models of diabetes mellitus. Diabet Med; 22:359-70.

[19]. Swain JE, Dunn RL, McConnell D, Gónzalez-Martínez J, Smith GD (2004). Direct effects of leptin on mouse reproductive function: regulation of follicular, oocyte, and embryo development. Biol Reprod; 71:1446-52.

[20]. Trout KK, Rickels MR, Schutta MH, et al (2007). Menstrual cycle effects on insulin sensitivity in women with type 1 diabetes: a pilot study. Diabetes Technol Ther; 9: 176-82. 